\title{
Boundary object or bridging concept? A citation network analysis of resilience
}

\author{
Jacopo A. Baggio ${ }^{1}$, Katrina Brown ${ }^{2}$ and Denis Hellebrandt ${ }^{3}$
}

\begin{abstract}
Many recent studies observe the increasing importance, influence, and analysis of resilience as a concept to understand the capacity of a system or individual to respond to change. The term has achieved prominence in diverse scientific fields, as well as public discourse and policy arenas. As a result, resilience has been referred to as a boundary object or a bridging concept that is able to facilitate communication and understanding across disciplines, coordinate groups of actors or stakeholders, and build consensus around particular policy issues. We present a network analysis of bibliometric data to understand the extent to which resilience can be considered as a boundary object or a bridging concept in terms of its links across disciplines and scientific fields. We analyzed 994 papers and 35,952 citations between them to reveal the connectedness and links between and within fields. We analyzed the network according to different fields, modules, and sub-fields, showing a highly clustered citation network. Analyzing betweenness allowed us to identify how particular papers bridge across fields and how different fields are linked. With the exception of a few specific papers, most papers cite exclusively within their own field. We conclude that resilience is to an extent a boundary object because there are shared understandings across diverse disciplines and fields. However, it is more limited as a bridging concept because the citations across fields are concentrated among particular disciplines and papers, so the distinct fields do not widely or routinely refer to each other. There are some signs of resilience being used as an interdisciplinary concept to bridge scientific fields, particularly in socialecological systems, which may itself constitute an emerging sub-field.
\end{abstract}

Key Words: bibliometric analysis; boundary object; bridging; citation; interdisciplinarity; network; resilience

\section{INTRODUCTION}

Since 2005, there has been a notable increase in the number of published papers that use the term "resilience", from different fields, including ecology, environmental sciences, engineering, economics, social sciences, and psychology and cognitive sciences. A recent bibliometric analysis (Xu and Marinova 2013) shows the increase in academic publications, especially since the early 1970s. However, the term "resilience" has greater reach beyond academia. The interest in resilience is also reflected by the number of times the term has been searched in Google (Fig. 1), indicating that from year to year, there is increased interest in the term "resilience". In 2014, the number of searches for "resilience" was $124 \%$ higher than in 2004.

\section{Definitions of resilience}

The popularity of the term "resilience" may be due in part to its malleability; resilience has different meanings, depending on the field and context in which it is used. A number of publications provide reviews of the different definitions and meanings of resilience (e.g., Folke 2006, Bahadur et al. 2011, Martin-Breen and Anderies 2011) and its expansion into different fields such as social sciences (Brown 2014). Although the definition is distinct in each field, all of the definitions relate to the ability of a system to respond to change while maintaining specific attributes (or functions and controls). In psychology, resilience can be defined as "the process of, capacity for, or outcomes of successful adaptation despite challenging or threatening circumstances" (Masten et al. 1990:426). In engineering, resilience can be defined as the ability of something to return to its original shape after it has been pulled, stretched, pressed, or bent; in other words, it is the capacity of a material to absorb energy when it is deformed drastically and then, upon release, to have this energy recovered
Fig. 1. Average number of searches by year for the term "resilience". Data were retrieved from http://www.google.com and are based on Google search trends. Average searches per year are scaled on a $0-100$ scale where 100 signifies the maximum number of weekly searches for the term "resilience" from 2004 to 2014 .

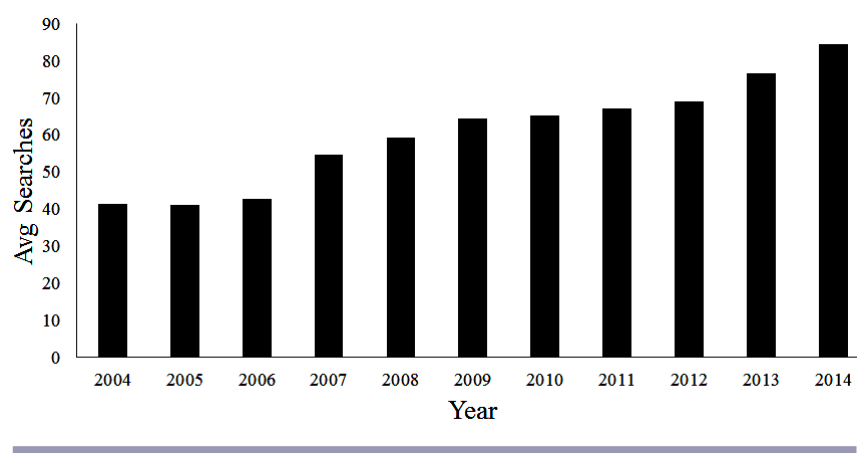

(Tredgold 1818, Mallet 1856). In the social-ecological systems field, the term "resilience" has evolved from the original ecological definition given by Holling (1973:14) "as a measure of the persistence of systems and of their ability to absorb change and disturbance and still maintain the same relationships between populations or state variables". Thus, Walker et al. (2004) refer to resilience as the ability of a social-ecological system to absorb disturbance and re-organize while undergoing change, so as to still retain essentially the same functions, structures, identity, and feedbacks. This interpretation of resilience can be thought of as a synthesis between a definition of resilience as the amount of 
Table 1. Definitions and characteristics of boundary objects and bridging concepts.

\begin{tabular}{lll}
\hline \hline Feature & \multicolumn{1}{c}{ Boundary object } & \multicolumn{1}{c}{ Bridging concept } \\
\hline Definition & $\begin{array}{l}\text { An entity shared by several different communities but viewed } \\
\text { or used differently by each of them (Star 1988) }\end{array}$ & A concept that actively links fields and stimulates dialog \\
Characteristic & $\begin{array}{l}\text { Interpretive flexibility: has different meanings in different } \\
\text { fields, and meanings may be negotiated over time (Van Pelt et } \\
\text { al. 2015) }\end{array}$ & $\begin{array}{l}\text { Fosters interdisciplinarity and transdisciplinarity (Deppisch } \\
\text { and Hasibovic 2013) }\end{array}$ \\
$\begin{array}{l}\text { Standardization of methods and measures develop as the } \\
\text { object moves between groups and across scales (Star 2010) } \\
\text { Dynamic between ill-structured and more tailored uses (Star } \\
\text { and Griesemer 1989) }\end{array}$ & $\begin{array}{l}\text { Bridges science and policy realms (DFID 2011) } \\
\text { (Davoudicet al. 2012) }\end{array}$ \\
\hline
\end{tabular}

disturbance that a system can undergo while maintaining its original functions and controls (Gunderson and Holling 2002), and resilience as the extent to which a social-ecological system is able to self-organize, learn, and adapt (Carpenter et al. 2001). Finally, resilience in economics can be defined as the ability of an economy (state, regional, local) to retain employment and wealth in face of disturbances such as the loss of a corporation or industry (Reggiani et al. 2002, Martin-Breen and Anderies 2011).

From these definitions, key similarities and differences can be identified across fields (Brown and Westaway 2011). Resilience always refers to persistence in face of disturbance; however, some fields refer to adaptation and learning (e.g., Carpenter et al. 2001, Walker et al. 2004), whereas others (as in engineering) refer to a return to a specific state (Holling 1996, Folke 2006, Brand and Jax 2007). A number of studies have analyzed different definitions of resilience and how they are the result of different traditions and fields of inquiry. The concept of resilience is wide and vague (Brand and Jax 2007). The generality of approaches and definitions of resilience depends on: (1) whether resilience is used as a descriptive concept having a clear, operational definition, or as a normative concept whereby the definition encompasses a wider array of characteristics (i.e., cultural values, political economy, politics); (2) the intentions with which the term is used; and (3) the traditions of the field in which specific research is developed (i.e., social science, ecology, engineering).

\section{Resilience as a boundary object}

These different meanings and interpretations suggest that resilience may be a boundary object, originally proposed by Star (1988) as an entity shared by several different communities but viewed or used differently by each of them (Table 1). Boundary objects allow for the coordination of different groups seeking consensus on aims and interests. They are valuable for different scientific fields and can be highly successful in fostering communication between different fields (van Pelt et al. 2015). Much discussion of boundary objects focuses on this interpretive flexibility, but Star (2010) reiterates that the standardization and the generation of residual categories are also important in the "growth and death" of boundary objects in a more dynamic sense. A boundary object acquires status through distinct interpretive communities, enabling them to transcend core differences in interpretation for the purposes of alignment required to perform particular work, and to cooperate without consensus. Although ill-structured across different groups, a boundary object can be precisely defined within a specific research group or field (Star and Griesemer 1989). Importantly, a boundary object links communities of practice to allow different groups to collaborate (Wenger 1998).

Brand and Jax (2007) analyze resilience as a boundary object. In addition to the different scientific fields, they categorize resilience according to its degree of normativity within a broadly defined sustainability science (Brand and Jax 2007; Table 1). From its original descriptive meaning, resilience is increasingly interpreted in a wider, more fluid or more malleable way, so that it moves beyond a concept or heuristic device to be presented as a "way of thinking" (Walker and Salt 2006, Brand and Jax 2007) and applied to analyze broader change in, for example, institutions, society, or political systems. In some respects, this suggests resilience as a broader theory of change. Depending on the intention and context of its research application, Brand and Jax (2007) suggest that resilience should be descriptive and be clearly defined for operational purposes, but also, that resilience should foster interdisciplinarity and collaboration across scientists belonging to different fields. This latter role of resilience is centered upon creating a shared vocabulary that facilitates communication across disciplinary borders, but perhaps involves trade-offs between clarity and precision of meaning. Resilience, as a broad term that is able to foster communication across disciplinary boundaries, can be interpreted as a boundary object.

\section{Resilience as a bridging concept}

Researchers have concentrated on the flexibility and precision trade-off or on specific definitions of the term resilience. Recently, a number of studies have also examined resilience as a bridging concept. Davoudi et al. (2012) discuss resilience as a bridging concept that is translated from the natural to the social world and then applied to planning. Deppisch and Hasibovic (2013) discuss the potential of resilience as a transdisciplinary concept in socialecological systems applied to climate change adaptation. The UK Department for International Development (DFID 2011) stresses the importance of resilience as a concept that bridges, or brings together in an integrative way, disaster risk reduction and longer term development. The emphasis here is on bridging between science and policy realms, as well as inter- or even transdisciplinary potential. The broad interpretation of resilience as an ensemble of ideas and theories on how to understand and analyze dynamics of complex systems in different fields may lead us to assume that resilience is a boundary object and therefore able to foster interdisciplinary collaboration. Resilience is thus proposed as a boundary object and a bridging concept, actually 
fostering communication and collaboration across fields, in other words, fostering interdisciplinarity.

Our analysis aims to further elaborate and test the various claims about resilience as a bridging concept or boundary object. We use the terms "boundary object" and "bridging concept" to gain an understanding of how resilience ideas are used across different areas and fields of study. Boundary objects and bridging concepts are similar, but have quite distinct features (Table 1). Rather than the discursive analysis undertaken by most previous studies, we analyze the term "resilience" and its ability to cross different disciplines or fields based on a bibliometric analysis. Our analysis departs from that of Janssen et al. (2006) and Janssen (2007) because we do not assume different fields such as resilience, vulnerability, and sustainability, but rather the analysis centers on the term "resilience" and how scholars who use the term in their work are related to each other. It extends the recent analysis by $\mathrm{Xu}$ and Marinova (2013) on trends in publications by looking at citations as a means of exploring the connections across fields. Analyzing citation patterns allows us to gain a quantitative understanding of whether resilience is actively used to bridge different disciplines. While conceptual analysis of the definition of resilience can shed light on the boundary nature of the term, conceptual and textual analyses cannot, on their own, shed light on the ability of resilience to act as a bridging concept.

Hereafter, we present our inclusive criteria and the metrics used in the citation network analysis. We then analyze the citation network using specific network metrics aimed at disentangling our main research question, i.e., Does resilience act as a bridging concept? Finally, we discuss some implications of our findings.

\section{METHODS}

\section{Searching for resilience}

Our literature search aimed to identify references to academic literature with an explicit focus on resilience that was published in the 2000s. No limits were imposed on fields or types of document, that is, results include all areas of knowledge, from natural to social sciences, and both peer-reviewed articles and references to "grey literature" (e.g., conference proceedings). We searched for articles with "resilience" in the title that were published between January 01, 2000 and April 01, 2012 in the following databases: SCI-EXPANDED (Science Citation Index Expanded), SSCI (Social Sciences Citation Index), A\&HCI (Arts and Humanities Citation Index), CPCI-S (Conference Proceedings Citation Index-Science), and CPCI-SSH (Conference Proceedings Citation Index-Social Science and Humanities).

The searches were carried out using the Web of Science service (ISI Thomson Reuters, access provided by the University of East Anglia, UK). Results comprised 3703 articles, which were retrieved as citation files in simple-text "full record" format, i.e., they included the full list of references cited per article.

\section{Citation network}

We excluded papers with $<10$ citations from our analysis. Because our primary aim was to assess whether resilience is a boundary and/or bridging object, we assumed that papers with $<10$ citations over the 12-yr period in our sample were not as of then acting as bridges. We are aware that by using any arbitrary cut-off, we create a bias toward older papers; however, we consider that a 10-citation cut-off allows us to concentrate on papers that are more relevant in specific disciplines. We note that very recent papers that do not meet our cut-off criteria could potentially be important bridging papers in the future.

Excluding papers with $<10$ citations resulted in 994 papers and 35,952 cross-citations between them. Our ensemble of papers and citations can be represented by an unweighted, directed network with 994 nodes and 35,952 edges (or citation links). Each of the 994 papers is assigned into one of five scientific fields: social sciences, ecology and environmental sciences, psychology, engineering, and social-ecological systems. In addition, there was a group of papers for which the specified field was not defined.

The papers were classified based on keywords, the journal in which they were published, author name, and abstract contents. We randomly selected 30 of the top 100 most cited papers and performed an inter-coder agreement test on that subset. The top 100 most cited make up the majority of cross-citations, and by examining one-third of those 100 , we were able to test the classification of a representative set of the overall sample. Three readers classified the papers independently, and the inter-coder reliability was assessed via the kappa statistic $(\mathrm{k}=0.752, P=0.05$; Fleiss 1971).

Having defined the major scientific fields, we also checked for structurally different modules, or parts of the network that are tightly connected within, and loosely connected to, other parts of the networks. In this context, a module defines a group of papers citing each other frequently (i.e., that have a high citation density), while they are cited by, or cite, few papers outside the group defined by the module (i.e., citation density toward nodes belonging to other modules is low). We assessed the pertinence of a node to a specific module using the Newman algorithm for modules detection and optimization (Newman 2006). The algorithm was run multiple times to assess its robustness, as suggested by Good et al. (2010).

\section{Network metrics}

We analyzed the importance of single nodes (papers) in the network using specific network metrics. We first assessed the overall importance of a node as a "bridge" to different fields using betweenness and closeness centrality measures. Betweenness centrality assesses the importance of a node in a network based on the "flow" it can control. In other words, a node (paper) with high betweennness centrality can be identified as an important paper bridging different sub-fields or fields of study. However, in a directed network, betweenness is calculated using out-edges or citation to other papers. To complement the information given by betweenness centrality, we also determined closeness centrality calculated using in-edges. Closeness centrality is used to calculate the "distance" between different nodes. A node is more globally central (or has a high closeness centrality) the shorter the path between node $i$ and other nodes.

Formally, betweenness is defined as:

$$
b_{i}=\frac{1}{(N-1)(N-2)} * \frac{\sum L_{h, i, j}}{L_{h, j}}
$$

Where $L_{\mathrm{i}, \mathrm{j}}$ is the total number of shortest paths from $i$ to $j ; L_{\mathrm{h}, \mathrm{i}, \mathrm{j}}$ is the number of shortest paths from $i$ to $j$ passing through node 
$h$; and $2(N-1)(N-2)$ is a normalization factor that maintains betweenness in the 0,1 interval. $N$ is the total number of nodes in the network.

Closeness is defined as:

$$
C c_{i}=\frac{1}{\sum_{j=1}^{n} d_{i, j}}
$$

Where the denominator represents the sum of the shortest distances between node $i$ and all other nodes in the network.

Although betweenness and closeness centrality can help to identify which papers are prominent in bridging different disciplines, neither centrality metric provides the ability to distinguish the role of papers within the belonging field and the overall network. To assess the role of papers within fields and within the overall citation network, we applied metrics defined by Guimerà and Nunes Amaral (2005). Their specific metrics are based on the idea that nodes with the same or similar role should have similar topological properties. Here, we focus on the participation coefficient. The participation coefficient $\left(P_{\mathrm{i}}\right)$ indicates how much a node participates in the connectivity to the overall network (i.e., has edges connecting to other modules) and assumes values in the 0,1 interval. A node whose edges only connect with nodes within its own module (field) will have a participation coefficient of 0 , whereas a node whose edges are uniformly distributed to nodes of other modules will have a participation coefficient of 1 .

Formally (from Guimerà and Nunes Amaral 2005),

$$
P_{i}=1-\sum_{S=1}^{N_{M}}\left(\frac{k_{i S}}{k_{i}}\right)^{2}
$$

Where $P_{\mathrm{i}}$ is the participation coefficient of node $i ; k_{\text {is }}$ is the number of edges of node $i$ to nodes in module $s ; k_{\mathrm{i}}$ is the total degree of node $i$; and ${ }^{\mathrm{N}} M$ is the number of modules or fields.

Finally, to analyze how fields are interconnected, we modified the participation coefficient and define a field-to-field participation metric as:

$$
P M_{i, m}=\frac{k_{i, m}}{k_{i}}
$$

Where $k_{\mathrm{i}, \mathrm{m}}$ are the edges connecting node $i$ to module $m$; and $k_{\mathrm{i}}$ is the degree (or total number of edges) of node $i$. Once the scores were calculated, we averaged the participation as defined by Eqn. 4 for all nodes belonging to a specific field to obtain a field-tofield connectivity matrix.

\section{RESULTS}

The citation network comprised 994 nodes and 35,952 edges (or citation links). The citation networks were represented per field (Fig. 2) and per module (Fig. 3). The size and sub-field for the modules were defined based on the Newman algorithm (Table 2, Fig. 2). Representative papers in Table 2 can be thought of as the most cited paper in a specific module or a key paper within a specific module. The overall density of the network is low (0.036), and the network is highly clustered (average clustering coefficient $=0.92$ ). On average, papers are cited and cite 36.14 times (average in and out degree). Apart from these general measurements, we analyzed in detail specific nodal properties that relate to our main focus of assessing whether resilience can be considered as a boundary object or a bridging concept. Betweenness and closeness centrality are the first nodal metrics that we consider to analyze the validity of resilience as a bridging concept. We report the 10 nodes with highest betweenness and closeness centrality scores (Table 3).

Fig. 2. Citation network among fields of study. Colors represent the major fields: pink $=$ social sciences; turquoise $=$ ecology and environmental sciences; orange = psychology; blue $=$ engineering; black $=$ social-ecological systems; yellow $=$ not defined.

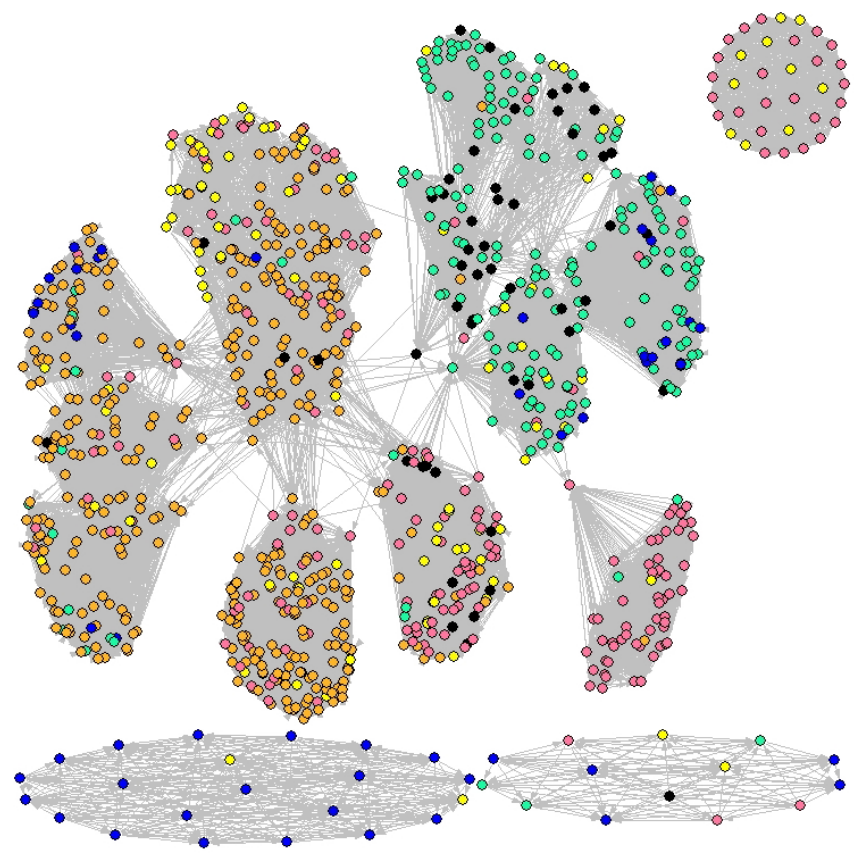

It is interesting to note how betweenness, based on the out-degree of a directed network, tends to favor newer papers, whereas closeness centrality tends to favor older papers. Betweenness centrality highlights the importance of papers that are cited and cite within different fields and sub-fields. The work of Sheffer et al. (2001) in Nature is a clear example of a paper that crosses different fields, as is the work in psychology of Masten (2001). In contrast, closeness centrality focuses on the importance of seminal papers such as Holling (1973) and Rutter (1985). As could have been expected, and is reported in other studies (Janssen et al. 2006, Xu and Marinova 2012), Holling"s (1973) paper is very central in the citation network. Holling (1973) opened the concept of resilience to different fields, and his later work expanded the notion of resilience from ecology to social-ecological systems. The analysis based on betweenness and closeness begs the question: Is resilience a bridging concept, or is resilience used independently by different fields? 
Table 2. Modules, frequencies of occurrence, and representative publications from the citation network. Module numbers correspond to Fig. 3.

\begin{tabular}{lccl}
\hline \hline Module & Frequency & Frequency $(\%)$ & Representative publication \\
\hline 1 & 147 & 14.79 & Alexander et al. 1993, Anxiety Stress and Coping \\
2 & 82 & 8.25 & Rutter 1985, British Journal of Psychiatry \\
3 & 26 & 2.62 & Freire 1970, Pedagogy Oppressed \\
4 & 59 & 5.94 & Homans 1958, American Journal of Sociology \\
5 & 60 & 6.04 & Kendler et al. 1999, American Journal of Psychiatry \\
6 & 60 & 6.04 & Holling 1973, Annual Review of Ecology and Systematics \\
7 & 47 & 4.73 & Scheffer et al. 2001, Nature \\
8 & 27 & 2.72 & Jackson et al. 2001, Science \\
9 & 14 & 1.41 & Rubinovitch 1985, Journal of Applied Probability \\
10 & 22 & 2.21 & Robinson 1972, IEEE Transaction \\
11 & 34 & 3.42 & DeWitt et al. 1998, Trends in Ecology and Evolution \\
12 & 35 & 3.52 & Ramsay 1977, Sociology \\
13 & 65 & 6.54 & Porsolt et al. 1978, European Journal of Pharmacology \\
14 & 64 & 6.44 & Blanchard and Blanchard 1989, Journal of Comparative Psychology \\
15 & 86 & 8.65 & Luthar et al. 2000, Child Development \\
16 & 93 & 9.36 & Glaser and Strauss 1967, Discovery Grounded Theory \\
17 & 73 & 7.34 & Pimm 1991, The balance of nature? Ecological issues in the conservation of species and communities \\
\hline
\end{tabular}

Fig. 3. Citation network among modules. Different colors indicate different modules. Field and modules exhibit some overlap; however, the division among different modules suggest the existence of sub-fields that are more closely connected.

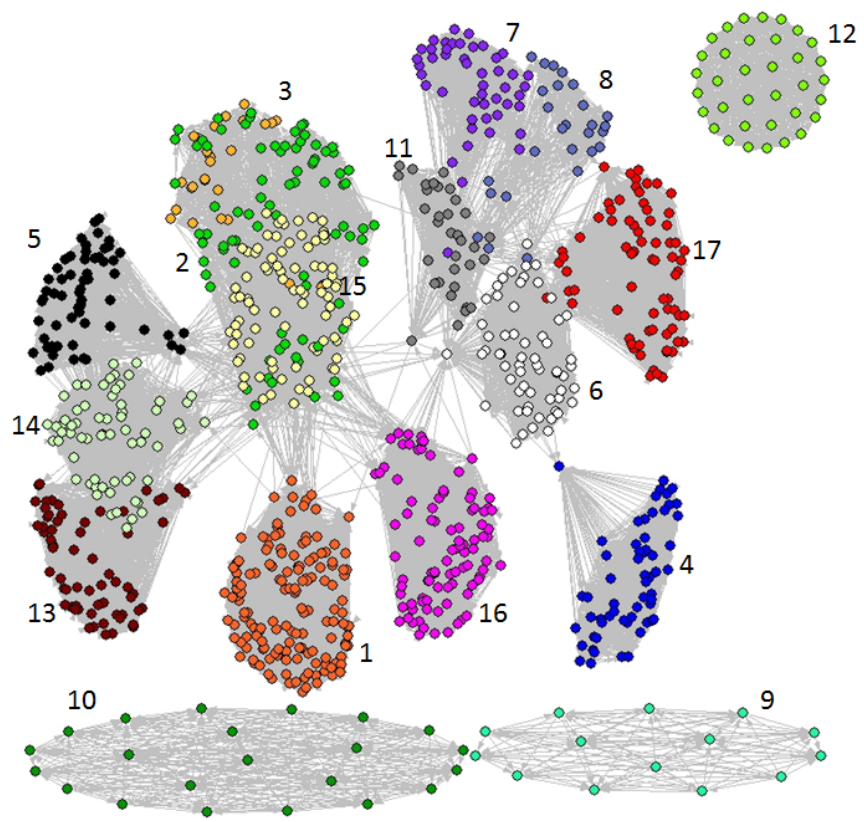

To shed light on the main research question, we first checked for differences between fields and modules defined by the Newman algorithm. As previously suggested by graphic inspection (Figs. 2 and 3), modules defined by the Newman algorithm are generally dominated by one field (Fig. 4). Engineering seems to be isolated from the rest of the literature that uses the term "resilience"; most of the papers classified as engineering belong to an isolated component (Mod 10). Social sciences can be divided into three main groups. The first group forms an isolated component of the network (Mod 12), whereas the second group is very loosely connected to the giant component of the network (Mod 4). The third group of papers classified as social science is linked to the social-ecological systems and psychology literature (nodes pertaining to Mod 16). Papers classified in the field of ecology and environmental science are also quite isolated (Mod 6, 7, and 17), except for citations with the social-ecological systems literature (especially Mod 11 and 8). Psychology mainly interacts with the social sciences, although the extent of this interaction seems to be restricted to specific sub-fields (Mod 2 and 3), whereas other sub-fields in psychology seem to be fairly isolated (i.e., nodes belonging to Mod 5, 13, 14, and 15). Finally, the social-ecological systems literature does not dominate any module and interacts mainly with the ecology and environmental sciences field.

Fig. 4. Percentage of papers within a specific field of study that pertain to modules defined by the Newman (2006) algorithm. Colors indicate fields of study: pink $=$ social sciences; turquoise = ecology and environmental sciences; orange = psychology; blue $=$ engineering; black $=$ social-ecological systems; yellow $=$ not defined.

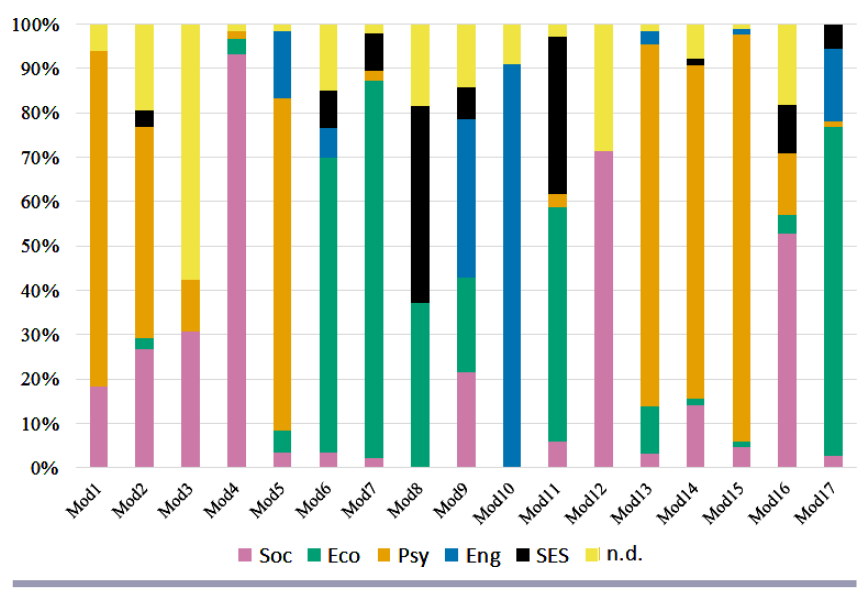


Table 3. Betweenness and closeness measures for the 10 nodes (publications) with highest scores in each metric.

\begin{tabular}{|c|c|c|c|}
\hline Betweenness & Score & Closeness & Score \\
\hline Bonanno 2004, American Psychologist & 0.026 & Glaser and Strauss 1967, Discovery Grounded Theory & 0.337 \\
\hline Masten 2001, American Psychologist & 0.012 & Holling 1973, Annual Review of Ecology and Systematics & 0.303 \\
\hline Scheffer et al. 2001, Nature & 0.012 & Rutter 1985, British Journal of Psychiatry & 0.258 \\
\hline Grossman et al. 2004, Journal of Psychosomatic Research & 0.011 & $\begin{array}{l}\text { Fried 1963, The urban condition: people and policy in the } \\
\text { metropolis }\end{array}$ & 0.246 \\
\hline Luthar et al. 2000, Child Development & 0.011 & $\begin{array}{l}\text { Dayton } 1972, \text { Proceedings of the colloquium on conservation } \\
\text { problems in Antarctica }\end{array}$ & 0.228 \\
\hline Willner 2005, Neuropsychobiology & 0.011 & $\begin{array}{l}\text { Murrell and Norris 1983, American Journal of Community } \\
\text { Psychology }\end{array}$ & 0.226 \\
\hline $\begin{array}{l}\text { Steinhardt and Dolbier 2008, Journal of American College } \\
\text { Health }\end{array}$ & 0.010 & Wagnild and Young 1993, Journal of Nursing Measurement & 0.221 \\
\hline Charney 2004, American Journal of Psychiatry & 0.009 & Luthar et al. 2000, Child Development & 0.221 \\
\hline Gallopín 2006, Global Environmental Change & 0.008 & Garmezy 1981, Further Explorations & 0.217 \\
\hline Grant et al. 2003, Psychological Bulletin & 0.007 & $\begin{array}{l}\text { Hamilton 1960, Journal of Neurology, Neurosurgery, and } \\
\text { Psychiatry }\end{array}$ & 0.215 \\
\hline
\end{tabular}

This analysis suggests a preference to cite within one's own field. Using the participation coefficient, we further checked this claim. All fields tended to cite mostly within their identified field of inquiry (i.e., $\geq 50 \%$ of papers have $P_{\mathrm{i}}<0.625$; Fig. 5). In our sample, very few papers cited exclusively within their own field $\left(P_{\mathrm{i}}=0\right)$, and none cited equally across fields $\left(P_{\mathrm{i}}>0.8\right.$, as expected from our previous analysis). The social-ecological systems field is more prone to cite across traditional disciplinary boundaries. The social science field is the field with highest variability with regard to the participation coefficient. These results (Figs. 4 and 5) showcase both very isolated fields (i.e., engineering) and fields that are more prone to be cited and cite outside their specific field (i.e., social-ecological systems). Citations are always biased toward the specific field of reference to which a paper belongs; however, within this bias, it is possible to see how different fields have a different degree of preference for in-field citation.

Fig. 5. Participation coefficient distribution for each field of study. In the boxplot, center lines indicate the median. Soc $=$ social sciences; eco = ecology and environmental sciences; psy = psychology; eng = engineering; $\mathrm{SES}=$ social-ecological systems; n.d. = not defined.

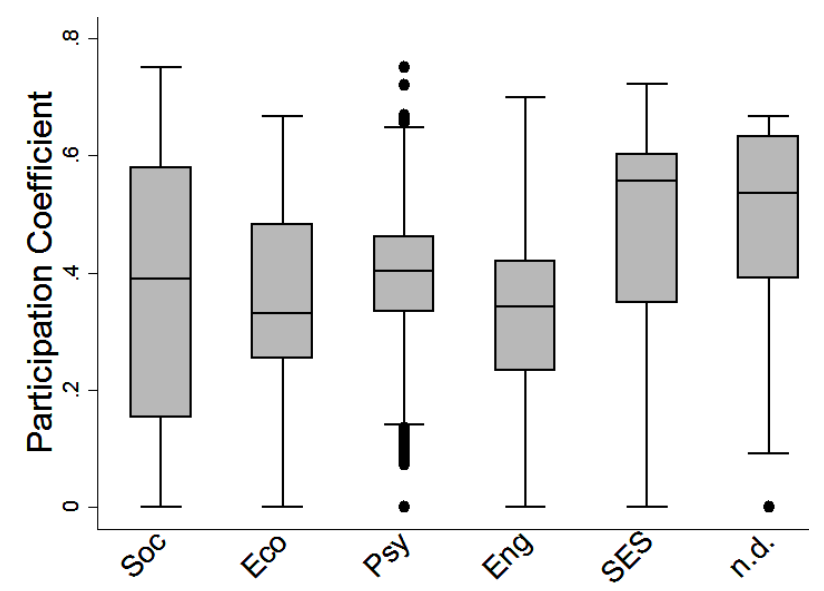

The field-to-field participation matrix confirms results from the preceding analysis (Fig. 6, Table 4). Psychology, social sciences, and ecology and environmental sciences are more exclusive in the use of the concept resilience and have less connection with other fields; all three have $>50 \%$ of edges that connect to papers in their own field. At the opposite end of the spectrum, the social-ecological systems literature is mostly connected with the ecology literature, and it is also the literature with fewest edges connecting to itself.

Fig. 6. Fraction of edges connecting fields of study. Soc = social sciences; ecol = ecology and environmental sciences; psy = psychology; eng = engineering; SES = social-ecological systems; n.d. = not defined.

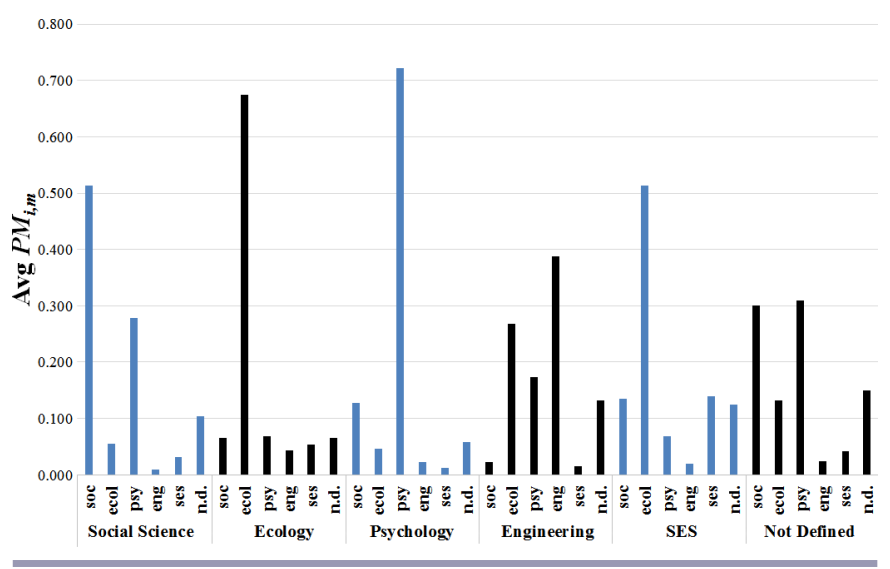

\section{DISCUSSION}

Our results suggest mixed evidence for resilience as a boundary object or a bridging concept. We can observe that resilience is, as Brand and Jax (2007) and others have suggested, a boundary object in so far as it can bring together different interests and stakeholders and loosely link ideas. It has also been used strategically as a bridging concept; for example, DFID (2011) refers to it as a concept to link disaster response and longer term development.

Resilience is clearly a boundary object to the extent that it is increasingly used with different meanings in a range of different 
Table 4. Descriptive statistics for field-to-field scores calculated using Eqn. 4.

\begin{tabular}{|c|c|c|c|c|c|c|c|c|}
\hline Field & "To" field $\uparrow$ & $N$ & Minimum & Maximum & Mean & $\mathrm{SD}$ & Median & $\begin{array}{c}\text { Inter-quartile } \\
\text { range } \\
\end{array}$ \\
\hline \multirow[t]{6}{*}{ Social science } & soc & 213 & 0.000 & 1.000 & 0.514 & 0.344 & 0.540 & 0.712 \\
\hline & ecol & 213 & 0.000 & 1.000 & 0.055 & 0.163 & 0.000 & 0.031 \\
\hline & psy & 213 & 0.000 & 1.000 & 0.279 & 0.322 & 0.128 & 0.636 \\
\hline & eng & 213 & 0.000 & 0.500 & 0.009 & 0.056 & 0.000 & 0.000 \\
\hline & ses & 213 & 0.000 & 0.333 & 0.031 & 0.059 & 0.000 & 0.045 \\
\hline & n.d. & 213 & 0.000 & 0.500 & 0.103 & 0.098 & 0.073 & 0.147 \\
\hline \multirow[t]{6}{*}{ Ecology } & soc & 185 & 0.000 & 0.962 & 0.066 & 0.125 & 0.038 & 0.065 \\
\hline & ecol & 185 & 0.000 & 1.000 & 0.675 & 0.281 & 0.769 & 0.198 \\
\hline & psy & 185 & 0.000 & 1.000 & 0.069 & 0.199 & 0.000 & 0.028 \\
\hline & eng & 185 & 0.000 & 0.800 & 0.043 & 0.095 & 0.000 & 0.077 \\
\hline & ses & 185 & 0.000 & 0.344 & 0.054 & 0.076 & 0.034 & 0.059 \\
\hline & n.d. & 185 & 0.000 & 1.000 & 0.066 & 0.103 & 0.031 & 0.125 \\
\hline \multirow[t]{6}{*}{ Psychology } & soc & 395 & 0.000 & 1.000 & 0.127 & 0.138 & 0.104 & 0.128 \\
\hline & ecol & 395 & 0.000 & 0.893 & 0.046 & 0.091 & 0.000 & 0.059 \\
\hline & psy & 395 & 0.000 & 1.000 & 0.721 & 0.202 & 0.750 & 0.108 \\
\hline & eng & 395 & 0.000 & 0.170 & 0.022 & 0.043 & 0.000 & 0.023 \\
\hline & ses & 395 & 0.000 & 0.333 & 0.012 & 0.036 & 0.000 & 0.000 \\
\hline & n.d. & 395 & 0.000 & 0.500 & 0.059 & 0.069 & 0.042 & 0.100 \\
\hline \multirow[t]{6}{*}{ Engineering } & soc & 53 & 0.000 & 0.143 & 0.022 & 0.030 & 0.000 & 0.034 \\
\hline & ecol & 53 & 0.000 & 0.860 & 0.269 & 0.348 & 0.065 & 0.692 \\
\hline & psy & 53 & 0.000 & 1.000 & 0.174 & 0.317 & 0.000 & 0.031 \\
\hline & eng & 53 & 0.000 & 0.909 & 0.388 & 0.372 & 0.140 & 0.769 \\
\hline & ses & 53 & 0.000 & 0.111 & 0.015 & 0.026 & 0.000 & 0.031 \\
\hline & n.d. & 53 & 0.000 & 1.000 & 0.133 & 0.211 & 0.100 & 0.154 \\
\hline \multirow[t]{6}{*}{ Social-ecological systems } & soc & 52 & 0.000 & 0.633 & 0.134 & 0.209 & 0.039 & 0.114 \\
\hline & ecol & 52 & 0.000 & 1.000 & 0.514 & 0.314 & 0.592 & 0.621 \\
\hline & psy & 52 & 0.000 & 0.571 & 0.068 & 0.131 & 0.016 & 0.073 \\
\hline & eng & 52 & 0.000 & 0.385 & 0.020 & 0.061 & 0.000 & 0.000 \\
\hline & ses & 52 & 0.000 & 0.435 & 0.140 & 0.131 & 0.096 & 0.228 \\
\hline & n.d. & 52 & 0.000 & 1.000 & 0.124 & 0.155 & 0.123 & 0.125 \\
\hline \multirow{6}{*}{ Not defined } & soc & 96 & 0.000 & 1.000 & 0.301 & 0.272 & 0.245 & 0.480 \\
\hline & ecol & 96 & 0.000 & 1.000 & 0.132 & 0.266 & 0.000 & 0.062 \\
\hline & psy & 96 & 0.000 & 1.000 & 0.310 & 0.305 & 0.184 & 0.551 \\
\hline & eng & 96 & 0.000 & 0.917 & 0.024 & 0.107 & 0.000 & 0.000 \\
\hline & ses & 96 & 0.000 & 0.458 & 0.042 & 0.086 & 0.000 & 0.067 \\
\hline & n.d. & 96 & 0.000 & 0.483 & 0.149 & 0.121 & 0.131 & 0.121 \\
\hline
\end{tabular}

$†$ Soc = social sciences; ecol = ecology and environmental sciences; $p$ sy = psychology; eng = engineering; ses = social-ecological systems; .d. $=$ not defined

fields. This is fairly well established in existing literature, and our brief review emphasizes the plurality of definitions. These meanings are being negotiated and re-negotiated and are changing over time, but there is no single agreed meaning across fields. Resilience displays the characteristics of a boundary object in being well structured or defined within a field, but very loosely defined across fields. There is some evidence, although limited, of interactions across fields, also shown by our bibliometric analysis. The analysis provides strong evidence to support the claims of resilience as a boundary object, but in somewhat limited ways. Resilience is definitely used across different fields with different meanings, and it displays interpretive flexibility. However, there are limited attempts at standardization across fields, and with citations only between specific fields, we can affirm that there is limited evolution from ill-structured to more tailored meanings, which are the second and third criteria for a boundary object (see Table 1).

To what extent then does resilience display the features of a bridging concept? Our analysis suggests that it does, but only to a limited degree and for specific fields. It provides what we might describe as a weak bridge between natural and social sciences. Our analysis of a citation network centered on the term "resilience" and of papers that have received $>10$ citations seems to contradict the bridging nature of the term itself, except perhaps for the social-ecological systems field, therefore indicating that it is a bridging concept in only a limited way. In particular, our analysis shows how the engineering field is the most isolated, with very rare and few citations to and from other fields, and mostly to genetic engineering and/or engineering applied to the neurosciences. Some sub-fields in the social sciences seem to be almost if not completely isolated (e.g., industrial organization and business). Furthermore, ecology and psychology seem mostly to interact only within their own field. One notable exception to this trend is the social-ecological systems literature. Perhaps because of its interdisciplinary origin, the social-ecological systems literature seems to be the most interacting field. It borrows from social sciences, engineering, psychology, and ecology. However, even within the social-ecological systems field, there is clear preferred connection to ecology. From the analysis undertaken, 
we can only speculate on why some fields and sub-fields are more isolated than others. In this context, academic tradition and the use in specific sub-fields of a descriptive definition of resilience that is tailored to the needs and intents of the research group and question is important. This might explain why the engineering field is more isolated, as in all likelihood, the definition of resilience is tailored to the problem at hand and is more likely to encompass technical systems or material science rather than social and ecological components. By the same token, economics and industrial organization fields are perhaps likely to operationalize resilience in very specific ways and thus not connect to the wider psychology-ecology-social-ecological systems literature. Further, when publishing in academic journals, researchers often tend to cite within the field or journal to which the paper to be published is targeted. This citation tradition is stronger in some fields than in others. In this context, papers classified as social-ecological systems are exempt because they belong to a nontraditional academic field.

We can affirm that there is a marked distinction in the use of resilience across fields; however, it is possible to highlight nuances and subtleties that have not been identified in previous studies. At present, the effectiveness of resilience as a bridging concept relies on a relatively small number of papers cited across fields. Our analysis contributes to understanding the multiple dimensions and strands of resilience research and how this balance plays out across the scientific literature. The term "resilience" is clearly isolated in certain fields, and this seemingly contradicts some previous claims to interdisciplinarity or its use as a bridging concept.

Although resilience seems not to have reached a true bridging concept status in academia, there are indications that it is perhaps more effective in certain policy arenas where the term resilience brings practitioners from different fields together. Our analysis of scientific papers and citations cannot inform the extent to which resilience bridges science and policy, or how it is used strategically to link different areas of work and practice. However, there is evidence that it does, even if only partially. For example, research by Brown (2012) has detailed how resilience concepts and terms are being applied in policy on climate change, environmental change, and international development. Here, resilience can be seen as a boundary object and as a bridging concept, with some development agencies using the term explicitly as a bridge. The World Bank (2009) uses resilience as a means of integrating climate change adaptation and mitigation. Christian Aid (2012) uses resilience to bring together disaster response and poverty alleviation agendas, and cites resilience as a bridging concept and as a means of finding integrated solutions to the interconnected problems. DFID (2011:5) refers to resilience as an "integrating concept" and a means to build bridges across its priority policy concerns of climate-proofing, resilient growth, and conflict and fragility. These observations support claims from other fields (e.g., planning; Davoudi et al. 2012) that resilience is a bridging concept between science and policy or practice.

\section{CONCLUSIONS}

We investigated the notion of resilience as a boundary object or a bridging concept. The potential interpretation of resilience as an ensemble of ideas and theories on how to understand and analyze dynamics of complex systems in different fields may lead one to think that resilience is a boundary object able to foster interdisciplinary collaboration. The rise of the term and its use across different fields would support it as a boundary object. However, our analysis of a citation network centered on the term "resilience" seems to contradict the bridging nature of the term itself, except perhaps for the social-ecological systems field, therefore indicating that it is a bridging concept in only a limited way. Although there are claims that it is effective as a bridging concept across science and policy and practice, Brown (2012) questions the extent to which this represents true innovation, rather than re-labelling of existing and conventional approaches.

The social-ecological systems field stands out as an emerging interdisciplinary arena where resilience can effectively act as a bridging concept and facilitate a discussion of dynamics of complex systems within varied contexts, informed by diverse perspectives, to provide potentially innovative theoretical and applied insights. This might have traction to inform the rapidly shifting policy adoption of resilience terminology and concepts.

\section{Responses to this article can be read online at: http://www.ecologyandsociety.org/issues/responses. $\mathrm{php} / 7484$}

\section{Acknowledgments:}

We are grateful to four anonymous reviewers for their comments and suggestions. Jacopo A. Baggio acknowledges support from the Center for Behavior, Institutions and the Environment at Arizona State University, and NSF Grant GEO-1115054. Katrina Brown acknowledges support from Economic and Social Research Council Professorial Fellowship "Resilient Development in SocialEcological Systems." All views and errors remain the responsibility of the authors. We thank DevCo at UEA for their support for this paper.

\section{LITERATURE CITED}

Alexander, C. N., G. C. Swanson, M. V. Rainforth, T. W. Carlisle, C. C. Todd, and R. M. Oates Jr. 1993. Effects of the transcendental meditation program on stress reduction, health, and employee development: a prospective study in two occupational settings. Anxiety, Stress and Coping 6(3):245-262. http://dx.doi. org/10.1080/10615809308248383

Bahadur, A. V., M. Ibrahim, and T. Tanner. 2011. The resilience renaissance? Unpacking of resilience for tackling climate change and disasters. Strengthening Climate Resilience Discussion Paper 1. Institute of Development Studies, Brighton, UK. [online] URL: http://opendocs.ids.ac.uk/opendocs/handle/123456789/2368.

Blanchard, R. J., and D. C. Blanchard. 1989. Antipredator defensive behaviors in a visible burrow system. Journal of Comparative Psychology 103(1):70-82. http://dx.doi. org/10.1037//0735-7036.103.1.70

Bonanno, G. A. 2004. Loss, trauma, and human resilience: Have we underestimated the human capacity to thrive after extremely aversive events? American Psychologist 59(1):20-28. http://dx.doi. org/10.1037/0003-066X.59.1.20 
Brand, F. S., and K. Jax. 2007. Focusing the meaning(s) of resilience: resilience as a descriptive concept and a boundary object. Ecology and Society 12(1): 23. [online] URL: http://www. ecologyandsociety.org/vol12/iss1/art23/.

Brown, K., 2012. Policy discourses of resilience. Pages 37-50 in M. Pelling, D. Manuel-Navarrete and M. Redclift, editors. Climate change and the crisis of capitalism: a chance to reclaim self, society and nature. Routledge, London, UK.

Brown, K. 2014. Global environmental change I: A social turn for resilience? Progress in Human Geography 38(1):107-117. http:// dx.doi.org/10.1177/0309132513498837

Brown, K., and E. Westaway. 2011. Agency, capacity, and resilience to environmental change: lessons from human development, well-being, and disasters. Annual Review of Environment and Resources 36:321-342. http://dx.doi.org/10.1146/ annurev-environ-052610-092905

Carpenter, S., B. Walker, J. M. Anderies, and N. Abel. 2001. From metaphor to measurement: Resilience of what to what? Ecosystems 4(8):765-781. http://dx.doi.org/10.1007/s10021-001-0045-9

Charney, D. S. 2004. Psychobiological mechanisms of resilience and vulnerability: implications for successful adaptation to extreme stress. American Journal of Psychiatry 161(2):195-216. http://dx.doi.org/10.1176/appi.ajp.161.2.195

Christian Aid. 2012. Thriving, resilient livelihoods: Christian Aid's approach. Christian Aid, London, UK. [online] URL: https:// www.christianaid.org.uk/Images/Resilient-livelihoods-briefingOctober-2012 tcm15-67261.pdf.

Davoudi, S., K. Shaw, L. J. Haider, A. E. Quinlan, G. D. Peterson, C. Wilkinson, H. Fünfgeld, D. McEvoy, and L. Porter. 2012. Resilience: a bridging concept or a dead end? Planning Theory and Practice 13(2):299-333. http://dx.doi.org/10.1080/14649357.2012 .677124

Dayton, P. K. 1972. Toward an understanding of community resilience and the potential effects of enrichments to the benthos at McMurdo Sound, Antarctica. Pages 81-96 in Proceedings of the colloquium on conservation problems in Antarctica. Allen Press, Lawrence, Kansas, USA.

Deppisch, S., and S. Hasibovic. 2013. Social-ecological resilience thinking as a bridging concept in transdisciplinary research on climate-change adaptation. Natural Hazards 67(1):117-127. http://dx.doi.org/10.1007/s11069-011-9821-9

DeWitt, T. J., A. Sih, and D. S. Wilson. 1998. Costs and limits of phenotypic plasticity. Trends in Ecology and Evolution 13 (2):77-81. http://dx.doi.org/10.1016/S0169-5347(97)01274-3

DFID [Department for International Development]. 2011. Defining disaster resilience: DFID approach paper. Department for International Development, London, UK. [online] URL: https:/www.gov.uk/government/publications/defining-disaster-resiliencea-dfid-approach-paper.

Fleiss, J. L. 1971. Measuring nominal scale agreement among many raters. Psychological Bulletin 76(5):378-382. http://dx.doi. org/10.1037/h0031619
Folke, C. 2006. Resilience: the emergence of a perspective for social-ecological systems analyses. Global Environmental Change 16(3):253-267. http://dx.doi.org/10.1016/j.gloenvcha.2006.04.002

Freire, P. 1970. Pedagogy of the oppressed. Translated by M. Bergman Ramos. Continuum, New York, New York, USA.

Fried, M. 1963. Grieving for a lost home. Pages 151-177 in L. J. Duhl, editor. The urban condition: people and policy in the metropolis. Basic Books, New York, New York, USA.

Gallopín, G. C. 2006. Linkages between vulnerability, resilience, and adaptive capacity, Global Environmental Change 16 (3):293-303. http://dx.doi.org/10.1016/j.gloenvcha.2006.02.004

Garmezy, N. 1981. Children under stress: perspectives on antecedents and correlates of vulnerability and resistance to psychopathology. Pages 196-269 in A. I. Rabin, J. Aronoff, A. M. Barclay, and R. Zucker, editors. Further explorations in personality. Wiley-Interscience, New York, New York, USA.

Glaser, B. G., and A. L. Strauss. 1967. The discovery of grounded theory: strategies for qualitative research. Aldine de Gruyter, Hawthorne, New York, USA.

Good, B. H., Y.-A. de Montjoye, and A. Clauset. 2010. Performance of modularity maximization in practical contexts. Physical Review E 81(4): 046106. http://dx.doi.org/10.1103/ PhysRevE.81.046106

Grant, K. E., B. E. Compas, A. F. Stuhlmacher, A. E. Thurm, S. D. McMahon, and J. A. Halpert. 2003. Stressors and child and adolescent psychopathology: moving from markers to mechanisms of risk. Psychological Bulletin 129(3):447-466. http:// dx.doi.org/10.1037/0033-2909.129.3.447

Grossman, P., L. Niemann, S. Schmidt, and H. Walach. 2004. Mindfulness-based stress reduction and health benefits: a metaanalysis. Journal of Psychosomatic Research 57(1):35-43. http:// dx.doi.org/10.1016/S0022-3999(03)00573-7

Guimerà, R., and L. A. Nunes Amaral. 2005. Cartography of complex networks: modules and universal roles. Journal of Statistical Mechanics: Theory and Experiment 2005(2): P02001. http://dx.doi.org/10.1088/1742-5468/2005/02/P02001

Gunderson, L. H., and C. S. Holling, editors. 2002. Panarchy: understanding transformations in human and natural systems. Island Press, Washington, D.C., USA.

Hamilton, M. 1960. A rating scale for depression. Journal of Neurology, Neurosurgery, and Psychiatry 23(1): 56-62. http://dx. doi.org/10.1136/innp.23.1.56

Holling, C. S. 1973. Resilience and stability of ecological systems. Annual Review of Ecology and Systematics 4:1-23. http://dx.doi. org/10.1146/annurev.es.04.110173.000245

Holling, C. S. 1996. Engineering resilience versus ecological resilience. Pages 31-44 in P. C. Schulze, editor. Engineering within ecological constraints. National Academy Press, Washington, D. C., USA.

Homans, G. C. 1958. Social behavior as exchange. American Journal of Sociology 63(6):597-606. http://dx.doi.org/10.1086/222355 
Jackson, J. B. C., M. X. Kirby, W. H. Berger, K. A. Bjorndal, L. W. Botsford, B. J. Bourque, R. H. Bradbury, R. Cooke, J. Erlandson, J. A. Estes, T. P. Hughes, S. Kidwell, C. B. Lange, H. S. Lenihan, J. M. Pandolfi, C. H. Peterson, R. S. Steneck, M. J. Tegner, and R. R. Warner. 2001. Historical overfishing and the recent collapse of coastal ecosystems. Science 293(5530):629-637. http://dx.doi.org/10.1126/science.1059199

Janssen, M. A. 2007. An update on the scholarly networks on resilience, vulnerability, and adaptation within the human dimensions of global environmental change. Ecology and Society 12(2): 9. [online] URL: http://www.ecologyandsociety.org/vol12/ iss $2 / \operatorname{art} 9 /$.

Janssen, M. A., M. L. Schoon, W. Ke, and K. Börner. 2006. Scholarly networks on resilience, vulnerability and adaptation within the human dimensions of global environmental change. Global Environmental Change 16(3):240-252. http://dx.doi. org/10.1016/j.gloenvcha.2006.04.001

Kendler, K. S., L. M. Karkowski, and C. A. Prescott. 1999. Causal relationship between stressful life events and the onset of major depression. American Journal of Psychiatry 156(6):837-841. http://dx.doi.org/10.1176/ajp.156.6.837

Luthar, S. S., D. Cicchetti, and B. Becker. 2000. The construct of resilience: a critical evaluation and guidelines for future work. Child Development 71(3):543-562. http://dx.doi.org/10.1111/1467-8624.00164

Mallet, M. 1856. On the physical conditions involved in the construction of artillery: an investigation of the relative and absolute values of the materials principally employed and of some hitherto unexplained causes of the destruction of the canon in service. Longman, Brown, Green, Longmans, and Roberts, London, UK.

Masten, A. S. 2001. Ordinary magic: resilience processes in development. American Psychologist 56(3):227-238. http://dx. doi.org/10.1037/0003-066X.56.3.227

Masten, A. S., K. M. Best, and N. Garmezy. 1990. Resilience and development: contributions from the study of children who overcome adversity. Development and Psychopathology 2:425-444. http://dx.doi.org/10.1017/S0954579400005812

Martin-Breen, P., and J. M. Anderies. 2011. Resilience: a literature review. Rockefeller Foundation, New York, New York, USA. [online] URL: http://www.rockefellerfoundation.org/media/ download/a63827c7-f22d-495c-a2ab-99447a8809ba.

Murrell, S. A., and F. H. Norris. 1983. Resources, life events, and changes in psychological states: a prospective framework. American Journal of Community Psychology 11(5):473-491. http://dx.doi.org/10.1007/BF00896800

Newman, M. E. J. 2006. Modularity and community structure in networks. Proceedings of the National Academy of Sciences 103 (23):8577-8582. http://dx.doi.org/10.1073/pnas.0601602103

Pimm, S. L. 1991. The balance of nature? Ecological issues in the conservation of species and communities. University of Chicago Press, Chicago, Illinois, USA.

Porsolt, R. D., G. Anton, N. Blavet, and M. Jalfre. 1978. Behavioural despair in rats: a new model sensitive to antidepressant treatments. European Journal of Pharmacology 47 (4):379-391. http://dx.doi.org/10.1016/0014-2999(78)90118-8

Ramsay, H. 1977. Cycles of control: worker participation in sociological and historical perspective. Sociology 11(3):481-506. http://dx.doi.org/10.1177/003803857701100304

Reggiani, A., T. De Graaff, and P. Nijkamp. 2002. Resilience: an evolutionary approach to spatial economic systems. Networks and Spatial Economics 2(2):211-229. http://dx.doi.org/10.1023/ A:1015377515690

Robinson, G. 1972. Logical convolution and discrete Walsh and Fourier power spectra. IEEE Transactions on Audio and Electroacoustics 20(4):271-280. http://dx.doi.org/10.1109/ TAU.1972.1162394

Rubinovitch, M. 1985. The slow server problem. Journal of Applied Probability 22(1):205-213. http://dx.doi.org/10.2307/3213760

Rutter, M. 2000. Resilience reconsidered: conceptual considerations, empirical findings, and policy implications. Pages 651-682 in J. P. Shonkoff and S. J. Meisels, editors. Handbook of early childhood intervention. Second edition. Cambridge University Press, Cambridge, UK. http://dx.doi.org/10.1017/ CBO9780511529320.030

Scheffer, M., S. Carpenter, J. A. Foley, C. Folke, and B. Walker. 2001. Catastrophic shifts in ecosystems. Nature 413 (6856):591-596. http://dx.doi.org/10.1038/35098000

Star, S. L. 1988. The structure of ill-structured problems: boundary objects and heterogeneous problem solving. Pages 2-37 in L. Gasser and M. Huhns, editors. Distributed artificial intelligence. Pitman, London, UK.

Star, S. L. 2010. This is not a boundary object: reflections on the origin of a concept. Science, Technology, and Human Values 35 (5):601-617. http://dx.doi.org/10.1177/0162243910377624

Star, S. L., and J. R. Griesemer. 1989. Institutional ecology, 'translations' and boundary-objects: amateurs and professionals in Berkeley's Museum of Vertebrate Zoology, 1907-39. Social Studies of Science 19(3):387-420. http://dx.doi.org/10.1177/030$\underline{631289019003001}$

Steinhardt, M., and C. Dolbier. 2008. Evaluation of a resilience intervention to enhance coping strategies and protective factors and decrease symptomatology. Journal of American College Health 56(4):445-453. http://dx.doi.org/10.3200/JACH.56.44.445-454

Tredgold, T. 1818. On the transverse strength of timber. Philosophical Magazine: Journal of Theoritical, Experimental and Applied Science Volume XXXXVII. Taylor and Francis, London, UK.

van Pelt, S. C., M. Haasnoot, B. Arts, F. Ludwig, R. Swart, and R. Biesbroek. 2015. Communicating climate (change) uncertainties: simulation games as boundary objects. Environmental Science and Policy 45:41-52. http://dx.doi. org/10.1016/j.envsci.2014.09.004

Wagnild, G. M., and H. M. Young. 1993. Development and psychometric evaluation of the Resilience Scale. Journal of Nursing Measurement 1(2):165-178. 
Walker, B., C. S. Holling, S. R. Carpenter, and A. Kinzig. 2004. Resilience, adaptability and transformability in social-ecological systems. Ecology and Society 9(5): 2. [online] URL: http://www. ecologyandsociety.org/vol9/iss2/art5/.

Walker, B., and D. Salt. 2006 Resilience thinking: sustaining ecosystems and people in a changing world. Island Press, Washington, D.C., USA.

Wenger, E. 1998. Communities of practice: learning, meaning, and identity. Cambridge University Press, Cambridge, UK. http://dx. doi.org/10.1017/CBO9780511803932

Willner, P. 2005. Chronic mild stress (CMS) revisited: consistency and behavioural-neurobiological concordance in the effects of CMS. Neuropsychobiology 52(2):90-110. http://dx. doi.

org/10.1159/000087097

World Bank. 2009. Word development report 2010: development and climate change. World Bank, Washington, D.C., USA. [online] URL: http://web.worldbank.org/WBSITE/EXTERNAL/EXTDEC/ EXTRESEARCH/EXTWDRS/0, contentMDK:23079906 pagePK:478093 piPK:477627 theSitePK:477624,00.html.

$\mathrm{Xu}$, L., and D. Marinova. 2013. Resilience thinking: a bibliometric analysis of socio-ecological research. Scientometrics 96(3):911-927. http://dx.doi.org/10.1007/s11192-013-0957-0 